\title{
Intermolecular Dissociation Energies of Dispersively Bound 1-Naphthol.Cycloalkane Complexes
}

\author{
Surajit Maity, Philipp Ottiger, Franziska A. Balmer, \\ Richard Knochenmuss and Samuel Leutwyler* \\ Departement für Chemie und Biochemie, Universität Bern, \\ Freiestrasse 3, CH-3000 Bern, Switzerland
}

(Dated: December 10, 2016)

\begin{abstract}
Intermolecular dissociation energies $D_{0}\left(S_{0}\right)$ of the supersonic jet-cooled complexes of 1-naphthol $(1 \mathrm{NpOH})$ with cyclopentane, cyclohexane and cycloheptane are determined to within $<0.5 \%$ using the stimulated-emission pumping resonant two-photon ionization method. The ground state $D_{0}\left(S_{0}\right)$ values are bracketed as $20.23 \pm 0.07 \mathrm{~kJ} / \mathrm{mol}$ for $1 \mathrm{NpOH} \cdot$ cyclopentane, $20.34 \pm 0.04 \mathrm{~kJ} / \mathrm{mol}$ for $1 \mathrm{NpOH} \cdot$ cyclohexane and $22.07 \pm 0.10 \mathrm{~kJ} / \mathrm{mol}$ for two isomers of $1 \mathrm{NpOH} \cdot \mathrm{cycloheptane.} \mathrm{Upon} S_{0} \rightarrow S_{1}$ excitation of the 1naphthol chromophore, the dissociation energies of the $1 \mathrm{NpOH} \cdot$ cycloalkane complexes increase by $0.1 \%$ to $3 \%$. Three dispersion-corrected density functional theory (DFT) methods predict that the cycloalkane moieties are dispersively bound to the naphthol face via London-type interactions, similar to the "face" isomer of the 1-naphthol-cyclopropane complex [J. Chem. Phys., 145, 164304 (2016)]. The experimental and calculated $D_{0}\left(S_{0}\right)$ values of the cyclohexane and cyclopentane complexes are practically identical, although the polarizability of cyclohexane is $\sim 20 \%$ larger than that of cyclopentane. Investigation of calculated pairwise atomic contributions to the D2 dispersion energy reveals that this is due to subtle details of the binding geometries of the cycloalkanes relative to the 1-naphthol ring. The B97-D3 DFT method predicts dissociation energies within about $\pm 1 \%$ of experiment, including the cyclopropane face complex. The B3LYP-D3 and $\omega$ B97X-D calculated dissociation energies are $7-9$ and $13-20 \%$ higher than the experimental $D_{0}\left(S_{0}\right)$ values. Without dispersion correction, all the complexes are calculated to be unbound.
\end{abstract}




\section{INTRODUCTION}

Intermolecular dispersion interactions are a topic of interest to many scientific communities. ${ }^{1-12}$ Dispersive interactions have been frequently used to explain physical, chemical and biological phenomena that range from crystal structures to conformations and binding of biomolecules. ${ }^{2-10,13}$ While relatively weak on a per-atom basis, two-body dispersion interactions are ubiquitous and are always attractive. ${ }^{14}$ The sum of all dispersive interactions can be substantial, on the same order of magnitude as electrostatic interactions. Theoretical and synthetic chemists have recognized that dispersion interactions can be employed as control elements for reactivity and catalysis, in particular, for larger molecules. ${ }^{10}$

Reliably accurate quantum chemical treatment of London dispersion interactions has proven to be a challenging problem. Theoretical progress requires high quality experimental data for benchmark systems that are computationally tractable, yet chemically relevant. ${ }^{11,12,15}$ Among the most relevant experimental observables is the intermolecular dissociation energy of a gas-phase bimolecular complex in its ground electronic state, $D_{0}\left(S_{0}\right)$. Unfortunately, the number of accurate $D_{0}$ measurements of dispersively bound complexes is limited up to now. ${ }^{12,16,17}$ The dissociation energies $D_{0}\left(S_{0}\right)$ of jet-cooled complexes of benzene with small alkanes, alkenes and halogenated hydrocarbons were determined to within about $10 \%$, using mainly mass-analyzed threshold ionization, dispersed fluorescence and two-color appearance potential techniques. ${ }^{13,18-22}$ The stimulated emission pumping-resonant two-photon ionization (SEP-R2PI) method developed by the Leutwyler group ${ }^{23-26}$ has been used to determine the ground-state dissociation energies of a series of dispersively bound complexes of the aromatic chromophores carbazole (with $\mathrm{Ne}, \mathrm{Ar}, \mathrm{Kr}, \mathrm{Xe}$, $\left.\mathrm{N}_{2}, \mathrm{CO}, \mathrm{CH}_{4}\right)^{23-26}$ and 1-naphthol $(1 \mathrm{NpOH})$, with cyclohexane, benzene ${ }^{27}$ and cyclopropane. ${ }^{28}$ Typical relative uncertainties of these $D_{0}$ values were smaller than $1 \% .^{23-28}$

Here we report the experimental dissociation energies $D_{0}\left(S_{0}\right)$ of $1 \mathrm{NpOH} \cdot$ cyclopentane and $1 \mathrm{NpOH} \cdot$ cycloheptane and a remeasurement of the $D_{0}$ of $1 \mathrm{NpOH} \cdot$ cyclohexane. $^{27}$ The latter was prompted by concerns regarding the previously reported $D_{0}\left(S_{0}\right)=2421 \pm 12 \mathrm{~cm}^{-1} \cdot{ }^{27,29}$ While the average molecular polarizabilities of cyclohexane $\left(\bar{\alpha}=10.9 \AA^{3}\right)$ and benzene $\left(\bar{\alpha}=10.0 \AA^{3}\right)$ are similar, the experimental dissociation energy of the $1 \mathrm{NpOH} \cdot$ benzene complex was much lower, $D_{0}\left(S_{0}\right)=1773 \pm 25 \mathrm{~cm}^{-1} \cdot{ }^{27}$ While the dispersive binding energy is not rigorously correlated with the average polarizability, the discrepancy was disturbing.

Remarkably, the corrected $1 \mathrm{NpOH} \cdot$ cyclohexane $D_{0}\left(S_{0}\right)$ is nearly identical to that of the 
$1 \mathrm{NpOH} \cdot$ cyclopentane complex, despite the additional methylene group of cyclohexane. However, adding another $\mathrm{CH}_{2}$ group in cycloheptane results in a substantial increase of $D_{0}\left(S_{0}\right)$. We show below that these unexpected trends in binding energy reflect the molecular structure and flexibility of the cycloalkane moieties as well as their specific binding geometries in the complex.

\section{METHODS}

\section{A. The SEP-R2PI Methods}

The dissociation energies of the ground electronic states of jet cooled molecular complexes were determined using the stimulated-emission pumping resonant two photon ionization (SEPR2PI) method. ${ }^{12,23-27,30-32}$ Detailed descriptions have been reported elsewhere. ${ }^{12,28}$ Briefly, a pulsed pump laser ( $\sim 5 \mathrm{~ns}$ pulse width) is fixed at the $S_{0} \rightarrow S_{1}$ electronic origin ( $0_{0}^{0}$ band) and excites the jet-cooled $\mathrm{M} \cdot \mathrm{X}$ complex from the vibrationless $S_{0}$ to the vibrationless $S_{1}$ state. After a short time delay ( $2-3 \mathrm{~ns}$ ), a dump laser is introduced that stimulated transitions back down to the $S_{0}$ state; this laser is scanned to lower photon energy than the $0_{0}^{0}$ band. If the dump laser is resonant with a vibronic transition, it transfers a part of the $S_{1} ; v^{\prime}=0$ population to a vibrationally excited level of the M.X $S_{0}$ state. These hot complexes undergo intramolecular and intra-complex vibrational redistribution (IVR), distributing the vibrational excess energy among the energetically accessible states. After a long delay of $1-3 \mu$ s for IVR to go to completion, the hot $\mathrm{M} \cdot \mathrm{X}$ complexes are probed by R2PI with a third pulsed dye laser. For the $D_{0}$ measurement, the probe laser is either fixed on the $0_{0}^{0}$ band or on a hot band. If the probe laser is on the origin, every resonant dump transition causes a decrease of the signal. The origin-probed SEP-R2PI spectrum are therefore essentially identical to the dispersed fluorescence (DF) spectrum from the $S_{1} ; v^{\prime}=0$ state of the $\mathrm{M} \cdot \mathrm{X}$ complex, but with negative-going peaks.

If the probe laser is tuned into the hot-band region, the SEP-R2PI ion signal shows an increase at every resonant dump transition to an $S_{0}$ vibrational level, but only if the hot $\mathrm{M} \cdot \mathrm{X}$ complex remains intact. If the dump laser transition leads to a high-lying metastable level that above the $S_{0}$ dissociation energy of the complex, IVR is followed by vibrational predissociation of the complex, the "hot" M.X population disappears and no hot-band signal is observed with the probe laser. The $D_{0}\left(S_{0}\right)$ of the complex is thereby bracketed between the highest vibrational level that is observed in the hot-band probed SEP-R2PI spectrum and next higher vibration that appears in the origin- 
probed SEP-R2PI or in the fluorescence spectrum. Additionally, when taking into account the frequency shift $\delta \tilde{\nu}$ of the $S_{0} \rightarrow S_{1}$ origin of M.S relative to that of M, the $D_{0}\left(S_{1}\right)$ is obtained from $D_{0}\left(S_{1}\right)=D_{0}\left(S_{0}\right)-\delta \tilde{\nu}^{23-27}$

\section{B. Experimental}

The $1 \mathrm{NpOH} \cdot$ cycloalkane complexes were produced in a pulsed supersonic molecular beam by co-expanding $1 \mathrm{NpOH}$ (Fluka, 99\%) and each of the cycloalkanes ( $0.2 \%$ cyclopentane, $0.1 \%$ cyclohexane, or $0.2 \%$ cycloheptane) premixed in neon carrier gas. The naphthol was heated to 353 $\mathrm{K}$, resulting in a vapor pressure of 0.5 mbar. The total backing pressure was $1.4-1.6$ bar. Two frequency-doubled tunable dye lasers (Lambda Physik FL2002 and FL3002, fundamental range $620-660 \mathrm{~nm})$ were employed as pump $(0.2 \pm 0.02 \mathrm{~mJ} / \mathrm{pulse})$ and dump $(2.2 \pm 0.2 \mathrm{~mJ} / \mathrm{pulse})$ lasers. Both were pumped by a single Nd:YAG laser (Quanta Ray DCR3). The probe dye laser (Lambda Physik LPD 3000, $0.25 \pm 0.02 \mathrm{~mJ} /$ pulse) was pumped by a Continuum Surelite II frequencydoubled Nd:YAG laser. The dye-laser bandwidths before frequency doubling were $0.3 \mathrm{~cm}^{-1}$. The wavelengths were monitored by a HighFinesse WS6 wavemeter. The probe laser was time-delayed by $1-3 \mu$ s and crossed the molecular beam $1-3 \mathrm{~mm}$ downstream of the pump and dump lasers. Other experimental details were the same as previously reported. ${ }^{23-28}$

Mass-selective one-color resonant two-photon ionization (R2PI) spectra were recorded using a $120 \mathrm{~cm}$ linear time-of-flight mass spectrometer. To identify isomeric complexes of the same mass, hole-burning spectroscopy was performed. $S_{1} \rightarrow S_{0}$ dispersed fluorescence spectra were measured by exciting the respective $0_{0}^{0}$ band. The fluorescence was collected with UV quartz optics and detected in second order with a SOPRA UHRS F1500 $1.5 \mathrm{~m}$ monochromator. The slit width was $200 \mu \mathrm{m}$, equivalent to a bandpass of $0.028 \mathrm{~nm}$; the fluorescence spectra were scanned with a step size of $0.0025 \mathrm{~nm}$.

\section{Theoretical Methods}

The $1 \mathrm{NpOH} \cdot$ cycloalkane complexes were calculated using three dispersion-corrected density functional methods with different functionals and dispersion corrections. The B3LYP-D3 method $^{33}$ was used with the TZVPP basis set, using TURBOMOLE 7.0. ${ }^{34}$ The $D_{0}\left(S_{0}\right)$ values for two different $1 \mathrm{NpOH} \cdot$ cyclopropane complexes calculated with this method agreed with the ex- 
perimental dissociation energy to within $1.1 \% .{ }^{28}$ In addition, we employed the B97-D3 method ${ }^{35}$ with the def2-TZVPP basis set, as implemented in TURBOMOLE 7.0, and the Chai and Gordon long-range and dispersion-corrected $\omega \mathrm{B} 97 \mathrm{X}-\mathrm{D}$ functional ${ }^{36}$ with the $6-31++\mathrm{G}(\mathrm{d}, \mathrm{p})$ basis set, as implemented in Gaussian 09. ${ }^{37}$ The latter two methods gave good results in a study of large $\pi$-stacked complexes. ${ }^{38,39}$

The earlier D2 dispersion-correction method of Grimme corrects the DFT method using atompairwise $C_{i j}^{(6)} / R_{i j}^{6}$ atom-atom interaction potentials, with $C_{i j}^{(6)}$ coefficients that depend on the pair of atoms $i$ and $j .{ }^{40}$ The D2 model will be used to calculated per-atom contributions to the dispersion interaction in section IV.B. The later D3 dispersion-correction method of Grimme ${ }^{33}$ uses carefully refined $C_{i j}^{(6)}$ coefficients which are scaled by a local "coordination number" corrections. ${ }^{11}$

All structure optimizations were unconstrained. With Gaussian09 we used the VERYTIGHT option. With TURBOMOLE, we used the following criteria that are tighter than standard: The thresholds for SCF and one-electron density convergence were $10^{-9}$ a.u. and $10^{-8}$ a.u., those for the structure optimizations were $10^{-8}$ a.u. for the energy change, $6 \cdot 10^{-6}$ a.u. for the maximum displacement element, $10^{-6}$ a.u. for the maximum gradient element, $4 \cdot 10^{-6}$ a.u. for the RMS displacement and $10^{-6}$ a.u. for the RMS gradient. The Cartesian coordinates of the ground state geometries of all complexes and the corresponding monomers optimized with B97D3/def2-TZVPP basis set are given in Tables S1-S14 in the Supporting Information.

The $\omega \mathrm{B} 97 \mathrm{X}-\mathrm{D} D_{e}$ values were corrected a posteriori for basis set superposition error (BSSE) using the Boys-Bernardi counterpoise correction. The BSSE correction for $D_{e}$ values is not recommended if the D3 method is used, ${ }^{35}$ and thus was not employed with B3LYP-D3 and B97-D3.

The harmonic frequencies and vibrational zero point energies (ZPVE) of the monomers and complexes were calculated with all three DFT methods at the same level as the optimized structures. From the calculated binding energies $D_{e}$ and changes in vibrational zero-point energy, $\triangle \mathrm{ZPVE}=\mathrm{ZPVE}($ complex $)-\mathrm{ZPVE}(1 \mathrm{NpOH})-\mathrm{ZPVE}($ cycloalkane $)$, we calculated the dissociation energies, $D_{0}=D_{e}-\Delta \mathrm{ZPVE}$. 


\section{RESULTS}

\section{A. R2PI spectra of 1-Naphthol-Cycloalkane complexes}

Figure 1 shows the one-color R2PI spectra of the bare 1-naphthol chromophore and of the 1naphthol-cycloalkane complexes in the region of the $S_{0} \rightarrow S_{1}$ origin. The weaker bands in the spectra are mainly due to excitation of low-frequency intermolecular vibrations in the $S_{1}$ state. For 1-naphthol-cyclopropane, the two strong peaks at 31384 and $31458 \mathrm{~cm}^{-1}$ have recently been assigned as the $S_{0} \rightarrow S_{1}$ origin bands of two isomers that were denoted "edge" and "face", ${ }^{28}$ see also section III.C. The $S_{0} \rightarrow S_{1}$ origin bands of the edge and face isomers exhibit spectral shifts $\delta \tilde{\nu}=-71.5 \mathrm{~cm}^{-1}$ and $+1.9 \mathrm{~cm}^{-1}$ compared to that of free $1 \mathrm{NpOH}$ at $31455.9 \mathrm{~cm}^{-1}$.

The R2PI spectrum of $1 \mathrm{NpOH} \cdot c y c l o p e n t a n e$ shows eight intense bands above the electronic origin, see Figure 1(c). Holeburning spectroscopy revealed that all bands originate from a single isomer, as shown in Figure S1 (supporting information). The strongest feature at $31404.6 \mathrm{~cm}^{-1}$ is assigned as the $S_{0} \rightarrow S_{1}$ origin band; it is shifted by $\delta \tilde{\nu}=-51.3 \pm 0.5 \mathrm{~cm}^{-1}$ relative to the origin of $1 \mathrm{NpOH}$. The bands at $18.4,28.2$ and $33.5 \mathrm{~cm}^{-1}$ above the origin are assigned to three intermolecular fundamental vibrations $\nu_{1}, \nu_{2}$ and $\nu_{3}$. The remaining bands can be assigned as overtones and combinations of these three fundamentals. The Franck-Condon factors of the intermolecular vibrational modes are unusually large compared to the other complexes, indicating a considerable geometry change upon electronic excitation. This raises interesting questions about possible pseudorotation of the cyclopentane moiety.

The R2PI spectrum of $1 \mathrm{NpOH} \cdot$ cyclohexane is shown in Figure 1(d). The intense band at $31454.2 \mathrm{~cm}^{-1}$ is assigned as the $S_{0} \rightarrow S_{1}$ origin. It is only slightly red shifted $(\delta \tilde{\nu}=-1.7 \pm 0.5$ $\mathrm{cm}^{-1}$ ) relative to $1 \mathrm{NpOH}$. The weaker bands to higher frequency are assigned as the intermolecular vibrations and originated from a single isomer, as reported previously. ${ }^{27}$ Similar to the $1 \mathrm{NpOH} \cdot$ cyclopentane complex, these bands can be assigned to overtones and combinations of the low-frequency intermolecular vibrations $\nu_{1}=14.3 \mathrm{~cm}^{-1}, \nu_{2}=25.0 \mathrm{~cm}^{-1}$ and $\nu_{3}=38.3 \mathrm{~cm}^{-1}$.

The $S_{0} \rightarrow S_{1}$ electronic origins of two isomers of the $1 \mathrm{NpOH} \cdot$ cycloheptane complex are indicated in Figure 1(e). The existence of two isomers, denoted A and B, was confirmed by UV/UV hole-burning spectroscopy; their separated (holeburned) spectra are given in Figure S2 (supporting information). The origins of the isomers are at $31417.4 \mathrm{~cm}^{-1}$ (isomer A) and $31423.0 \mathrm{~cm}^{-1}$ (isomer B), these are shifted by $\delta \nu=-38.5 \mathrm{~cm}^{-1}$ and $-32.9 \mathrm{~cm}^{-1}$ relative to the $0_{0}^{0}$ band of 
$1 \mathrm{NpOH}$.

\section{B. Experimental Dissociation Energies}

Figure 2(a) shows the hot-band probed SEP-R2PI spectrum of the $1 \mathrm{NpOH} \cdot$ cyclopentane complex, with the probe laser set to $0_{0}^{0}-62 \mathrm{~cm}^{-1}$, where a broad hot-band signal is observed. The dispersed fluorescence spectrum of $1 \mathrm{NpOH} \cdot c y c l o p e n t a n e$ is shown in Figure 2(b); it is inverted for easier comparison with the SEP-R2PI spectrum in (a). Within the experimental resolution of the fluorescence spectrum, both spectra in Figure 2 exhibit similar vibronic structure. In the hot-band probed SEP-R2PI spectrum, the highest energy vibrational band is at $1684.7 \mathrm{~cm}^{-1}$, which represents a lower limit for $D_{0}\left(S_{0}\right)$. The lowest-energy band in the fluorescence spectrum that is not observed in Figure 2(a) lies at $1697.1 \mathrm{~cm}^{-1}$. This is the upper limit to $D_{0}$; the wavenumber values of these two bands bracket the $D_{0}\left(S_{0}\right)$ of the $1 \mathrm{NpOH} \cdot$ cyclopentane complex as $1691 \pm 6 \mathrm{~cm}^{-1}$ or $20.23 \pm 0.07 \mathrm{~kJ} / \mathrm{mol}$. The excited-state dissociation energy $D_{0}\left(S_{1}\right)$ is obtained by subtracting the

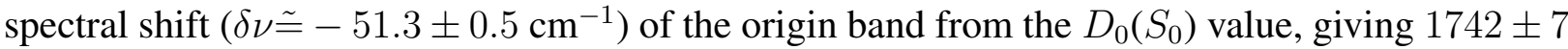
$\mathrm{cm}^{-1}$ or $20.84 \pm 0.08 \mathrm{~kJ} / \mathrm{mol}$, see also Table I. Note that the value after the \pm sign gives the bracketing interval; the true dissociation energy can lie anywhere within the bracketed interval.

Figure 3(a) shows the hot-band probed SEP-R2PI spectrum of $1 \mathrm{NpOH} \cdot$ cyclohexane, with the detection laser set to $0_{0}^{0}-65 \mathrm{~cm}^{-1}$; the corresponding origin-probed spectrum is shown in Figure 3(b). The highest-energy band in Figure 3(a) is at $1697.5 \mathrm{~cm}^{-1}$ and represents the lower limit for $D_{0}\left(S_{0}\right)$. In the origin-probed SEP-R2PI spectrum Figure 3(b) the band structure is nearly identical to that of spectrum (a) up to the last positive band at $1697.5 \mathrm{~cm}^{-1}$. The next significant band at $1703.2 \mathrm{~cm}^{-1}$ is missing in spectrum (a). This leads to a ground-state dissociation energy of $D_{0}\left(S_{0}\right)=1700 \pm 3 \mathrm{~cm}^{-1}$ or $20.34 \pm 0.04 \mathrm{~kJ} / \mathrm{mol}$. Because of the very small $\delta \tilde{\nu}$ of $-1.7 \mathrm{~cm}^{-1}$, the excited-state intermolecular dissociation energy $D_{0}\left(S_{1}\right)=1702 \pm 3 \mathrm{~cm}^{-1}$ or $20.36 \pm 0.04 \mathrm{~kJ} / \mathrm{mol}$, nearly the same as $D_{0}\left(S_{0}\right)$, see also Table I.

The $D_{0}\left(S_{0}\right)$ value for $1 \mathrm{NpOH} \cdot c y c l o h e x a n e$ is $719 \mathrm{~cm}^{-1}$ smaller than the previously reported value of $2421 \mathrm{~cm}^{-1} .{ }^{27}$ In ref. 27 higher concentrations of 1-naphthol and cyclohexane were used in the previous work to achieve a sufficient signal-to-noise ratio, but unfortunately, that also increased the relative populations of larger clusters $(1 \mathrm{NpOH})_{n} \cdot(\text { cyclohexane })_{m}$. In the one-color R2PI process, sufficient excess energy may have been deposited in the ion state to induce cluster fragmentation. It is likely that in ref. 27 the dissociation energy of a larger cluster was inadver- 
tently measured because of efficient fragmentation into the $1 \mathrm{NpOH} \cdot$ cyclohexane ${ }^{+}$mass channel.

As noted above, two isomers of the $1 \mathrm{NpOH} \cdot$ cycloheptane complex were observed by R2PI with roughly equal intensities. Figure 4(a) shows the hot-band probed SEP-R2PI spectrum of isomer $\mathrm{B}$ with the detection laser set to $0_{0}^{0}-83 \mathrm{~cm}^{-1}$, which is compared to the inverted fluorescence spectrum in Figure 4(b). The corresponding spectra for isomer A are shown in Figure S3 (supporting information). The ground state dissociation energy is bracketed between the highest-energy vibrational band $\left(1837.8 \mathrm{~cm}^{-1}\right)$ in the hot-band probed SEP-R2PI and the nearest higher energy band in the fluorescence spectrum $\left(1852.4 \mathrm{~cm}^{-1}\right)$. The ground state binding energy of isomer $\mathrm{A}$ is bracketed by the analogous two bands, so both isomers have identical $D_{0}\left(S_{0}\right)=1845 \pm 8 \mathrm{~cm}^{-1}$. Due to the different spectral shifts of the electronic origins of the two isomers relative to that of $1 \mathrm{NpOH}$, the excited state binding energies $D_{0}\left(S_{1}\right)$ differ by $0.06 \mathrm{~kJ} / \mathrm{mol}$, yielding $D_{0}\left(S_{1}\right)=22.53 \pm 0.11 \mathrm{~kJ} / \mathrm{mol}$ for isomer A and $22.47 \pm 0.11 \mathrm{~kJ} / \mathrm{mol}$ for isomer $\mathrm{B}$, see Table I.

\section{Calculated Structures}

As will be shown below, the $S_{0}$ state dissociation energies calculated with the B97-D3 method are closer to experiment than those calculated with the B3LYP-D3 and the $\omega$ B97X-D methods. We therefore discuss only the B97-D3 calculated structures, but note that the B3LYP-D3 and $\omega \mathrm{B} 97 \mathrm{X}-\mathrm{D}$ calculated structures are very similar. Figures 5 and 6 show the calculated structures of the complexes. The corresponding Cartesian coordinates are given Tables S1-S14 (supporting information). The calculated structures of the edge and face isomers of the $1 \mathrm{NpOH} \cdot$ cyclopropane complex have been previously reported. ${ }^{28}$

For $1 \mathrm{NpOH} \cdot c y c l o p e n t a n e$, two face isomers are predicted, related by rotation or pseudorotation of the cyclopentane. The dissociation energies differ by only $0.3 \mathrm{~kJ} / \mathrm{mol}$. Because the barrier to pseudorotation is practically zero in free cyclopentane, ${ }^{41}$ it is conceivable that pseudorotational interconversion between these two isomers might occur in the $1 \mathrm{NpOH} \cdot$ cyclopentane complex even at the low vibrational temperature in the supersonic beam expansion $\left(T_{v i b} \sim 5-10 \mathrm{~K}\right)$. However, the treatment of these dynamics is beyond the scope of this work; here we discuss the complex in terms of a static structure. The cyclopentane moiety is predicted to be in a "flap-up" conformation laterally displaced from a position above the center of the aromatic system towards the hydroxyl and tilted downwards toward the $\mathrm{OH}$ group, see Figure 5. This displacement and tilt is a common 
motif in all the face bound cycloalkane complexes. The average distance from the naphthol plane to the four "envelope" $\mathrm{C}$ atoms of cyclopentane that lie roughly in the same plane is $3.58 \AA$, see Table S7 (supporting information). The $\mathrm{H}$ atoms are tilted away from the normal to the naphthol plane at various angles. The three closest hydrogens are on average $2.56 \AA$ above the naphthol. While the displacement and tilting toward the hydroxyl and its associated dipole might be taken to indicate an electrostatic binding component, we note that the oxygen atom has a large dispersive attraction, compared to the hydrogens elsewhere around the naphthalene ring.

For $1 \mathrm{NpOH} \cdot c y c l o h e x a n e$, a variety of edge and face starting geometries all relaxed to the same face-type structure shown in Figure 5 with the cyclohexane in the chair conformation. No complexes with twist-boat or boat cyclohexane were predicted. The cyclohexane moiety is displaced and tilted towards the $\mathrm{OH}$ group, with the center-of-mass approximately above $\mathrm{C} 9$. The first layer of hydrogen atoms of these two complexes are on average almost equidistant from the naphthol, $2.56 \AA$ for cyclopentane and $2.57 \AA$ for cyclohexane. However, because the axial hydrogens of the chair cyclohexane point directly toward the naphthol, the closest carbon plane is $0.077 \AA$ farther away from the naphthalene plane compared to cyclopentane.

In the gas phase, the most stable conformation of cycloheptane is the "twist-chair", with a $C_{2}$ symmetry axis. ${ }^{42}$ This twist-chair conformation is predicted to occur in all of the calculated $1 \mathrm{NpOH} \cdot$ cycloheptane complexes, no optimization led to the second-lowest chair conformer ${ }^{42}$ of cycloheptane. The four lowest-energy conformations of 1-naphthol-cycloheptane shown in Figure 6 differ by small rotational and translational displacements of the cycloheptane above the naphthol plane. The lowest energy conformation (A) includes a $\mathrm{CH}_{2}$ group tilted toward the lone pair of the 1-naphthol OH group. The closest carbon atom is only $3.4 \AA$ above the naphthol plane, the next closest two $\mathrm{C}$ atoms are at $3.6 \AA$. In the second lowest energy conformation (B), the cycloheptane is shifted so that a $\mathrm{CH}_{2}$ group is almost directly above the hydroxyl oxygen. However, this group is less tilted, so that the nearest three $\mathrm{C}$ atoms are at $\sim 3.6 \AA$ above the naphthol plane.

\section{Comparison of Calculated and Experimental Dissociation Energies}

The dissociation energies of the cycloalkane complexes calculated with three density functional methods are given in Table II and shown in Figure 7. We have assigned the two experimentally observed isomers of $1 \mathrm{NpOH} \cdot$ cycloheptane to the two most stable calculated isomers A and B.

The B97-D3 calculated dissociation energies are seen to be in very good agreement with the 
experimental $D_{0}\left(S_{0}\right)$ values of all six complexes; the mean signed deviation is $+0.11 \mathrm{~kJ} / \mathrm{mol}$ and the maximum deviation is $+0.40 \mathrm{~kJ} / \mathrm{mol}$. Although the B3LYP-D3 calculated $D_{0}$ values agreed well for both the edge and face $1 \mathrm{NpOH} \cdot$ cyclopropane complexes,${ }^{28}$ the calculated $D_{0} \mathrm{~s}$ for the larger cycloalkanes are $7-9 \%$ larger than the experimental values. The $\omega$ B97X-D dissociation energies are uniformly too high by $15-20 \%$. In this case, the difference may be due to the simpler -D algorithm which lacks the coordination number correction of the D3 method. ${ }^{11,33}$

The difference in zero-point vibrational energy ( $\triangle \mathrm{ZPVE}$, defined in sect. II.C) ranges from $20 \%$ of $D_{0}$ for $1-\mathrm{NpOH}$-cyclopropane to $14 \%$ of $D_{0}$ for the cycloheptane complex. In Table II we list the B97-D3 calculated $\triangle$ ZPVEs; those calculated with the other two methods are very similar. Clearly, the $\triangle \mathrm{ZPVE}$ corrections are substantial and mandatory for accurate calculation of $D_{0}$. Roughly half of $\triangle \mathrm{ZPVE}$ arises from the additional six intermolecular vibrations, the rest comes from the sum over all the changes of ZPVE of the intramolecular vibrations of the $1 \mathrm{NpOH}$ and cycloalkane moieties.

All methods predict four energetically close-lying structures for the $1 \mathrm{NpOH} \cdot$ cycloheptane complex, see Figure 6. The B97-D3 and B3LYP-D3 methods agree on the energy ordering of the four isomers; the $\omega \mathrm{B} 97 \mathrm{X}-\mathrm{D}$ method predicts the isomers denoted $\mathrm{B}$ and $\mathrm{C}$ to be the lowest two minima. Below, we will assume that the B97-D3 and B3LYP-D3 ordering is correct. The interconversion barrier between the two predicted face isomers of the $1 \mathrm{NpOH} \cdot$ cyclopropane complex is only $1.4 \mathrm{~kJ} / \mathrm{mol},{ }^{28}$ so it is likely that the isomerization barriers between the four face isomers of $1 \mathrm{NpOH} \cdot$ cycloheptane are in the range of $1-2 \mathrm{~kJ} / \mathrm{mol}$ and can be surmounted even at late stages of the supersonic expansion. This would also explain why so far only two isomers have been experimentally observed.

In Table III we compare the magnitude of the D3 dispersion contribution to the total B97-D3 calculated binding energy $D_{e}$. The D3 dispersion energy is a large or dominant part of the binding energy in every case. Without the D3 dispersive contribution, only the non-classically H-bonded cyclopropane "edge" complex would remain bound, ${ }^{28}$ and even in that case the non-dispersive part of $D_{e}$ is small. Clearly the binding of these complexes is completely dominated by dispersive interactions. 


\section{DISCUSSION}

\section{A. Complex structures and spectral shifts}

We have used the spectral shift of the $S_{0} \rightarrow S_{1}$ origin band, $\delta \tilde{\nu}$, as a qualitative indicator of the binding topology of $1 \mathrm{NpOH} \cdot \mathrm{S}$ intermolecular complexes. ${ }^{28}$ In the $1 \mathrm{NpOH} \cdot \mathrm{Ar}$ and $1 \mathrm{NpOH} \cdot \mathrm{N}_{2}$ complexes the interaction is dominantly or purely dispersive, the Ar or $\mathrm{N}_{2}$ moiety is adsorbed on the aromatic face of $1 \mathrm{NpOH}$, and the experimental spectral shifts are small, $\delta \tilde{\nu}=-15 \mathrm{~cm}^{-1}$ and $-14 \mathrm{~cm}^{-1}$, respectively. ${ }^{43}$ Similarly, the face isomer of $1 \mathrm{NpOH} \cdot$ cyclopropane exhibits a small spectral shift to the blue, $\delta \tilde{\nu}=+2 \mathrm{~cm}^{-1} .{ }^{28}$ In contrast, the spectral shifts are always to the red and larger if the solvent molecule is $\mathrm{H}$-bonded to the naphthol $\mathrm{OH}$ group, as in the complexes with $\mathrm{H}_{2} \mathrm{O}\left(\delta \tilde{\nu}=-145 \mathrm{~cm}^{-1}\right), \mathrm{D}_{2} \mathrm{O}\left(\delta \tilde{\nu}=-144 \mathrm{~cm}^{-1}\right)$, methanol $\left(\delta \tilde{\nu}=-158 \mathrm{~cm}^{-1}\right)$, ethanol $\left(\delta \tilde{\nu}=-154 \mathrm{~cm}^{-1}\right)$, oxirane $\left(\delta \tilde{\nu}=-126 \mathrm{~cm}^{-1}\right)$, oxetane $\left(\delta \tilde{\nu}=-184.2 \mathrm{~cm}^{-1}\right)$ and $\mathrm{NH}_{3}(\delta \tilde{\nu}=$

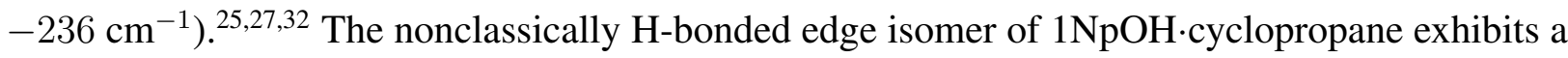
red shift of $-71.5 \mathrm{~cm}^{-1}$, about half that of the $1 \mathrm{NpOH} \cdot \mathrm{H}_{2} \mathrm{O}$ complex. ${ }^{28}$.

The spectral shift for $1 \mathrm{NpOH} \cdot$ cyclohexane is $\delta \tilde{\nu}=-1.7 \mathrm{~cm}^{-1}$, similar to that of the face isomer of cyclopropane, suggesting a face-bound isomer. In contrast, the spectral shift of $1 \mathrm{NpOH} \cdot$ cyclopentane is $\delta \tilde{\nu}=-51 \mathrm{~cm}^{-1}$. This red shift is $\sim 70 \%$ of that of the $1 \mathrm{NpOH} \cdot$ cyclopropane edge isomer, and is unusually large for a face-type complex. On the other hand, it is substantially smaller than the edge hydrogen-bonded $1 \mathrm{NpOH}$ complexes with $\mathrm{H}_{2} \mathrm{O}, \mathrm{CH}_{3} \mathrm{OH}$, and $\mathrm{NH}_{3}$. The spectral shifts of the cycloheptane complex isomers A and B are -33 and $-39 \mathrm{~cm}^{-1}$ and are intermediate between the shifts of the cyclopropane face isomer and the cyclohexane complex. In summary, it appears that the spectral shift $\delta \tilde{\nu}$ is a reliable indicator of binding topology for small solvent molecules, but becomes more ambiguous for the larger ones.

\section{B. Molecular and atomistic models for dispersive interactions}

In the London expression for dispersive interactions, the long-range energy between two atoms is proportional to the dipole polarizabilities of the atoms. ${ }^{14}$ As reviewed by Grimme ${ }^{11}$ this can be generalized to molecules. Thus, the average molecular polarizability $\bar{\alpha}$ is often employed as a convenient proxy for the strength of dispersive interactions at medium to long range, ${ }^{13,44-46}$ although at short distances the approximation must break down.

In Figure 8 we plot the $D_{0}\left(S_{0}\right)$ of the $1 \mathrm{NpOH} \cdot$ cycloalkane complexes vs. the $\bar{\alpha}$ of the cy- 
cloalkane, ${ }^{47}$ see Table III. The $\bar{\alpha}$ value for cycloheptane was estimated from structure-property relationships. ${ }^{48}$ The correlation between the experimental dissociation energies and the line corresponding to the London equation is quite poor for the four cycloalkanes complexes discussed here. Most remarkably, the $D_{0}$ values for $1 \mathrm{NpOH} \cdot$ cyclopentane and $1 \mathrm{NpOH} \cdot$ cyclohexane differ by only $0.5 \%$, while the respective average polarizabilities differ by $\sim 20 \%$. Clearly, $\bar{\alpha}$ is not a useful predictor for the dissociation energy of these complexes.

In a better approximation, the dispersive interaction between two molecules can be expressed as a sum over pairwise atom-atom potentials, the two-body contributions being summed over all distinct atom pairs. This time-honored approach ${ }^{45,49,50}$ has been used to correct DFT methods for the lacking long-range dispersive attraction, for instance in the D2 and D3 methods, see section II.C. ${ }^{11,33,40}$ Here, we are interested in the relative contributions of the $\mathrm{C}, \mathrm{H}$ and $\mathrm{O}$ atoms of the $1 \mathrm{NpOH}$ and cycloalkane moieties to the total dispersion energy. Our goal is to explain why facebound cyclopentane is bound just as strongly as cyclohexane, although one expects the larger and more polarizable cyclohexane to have larger dispersive interactions. For this we employed the computationally simpler D2 method and the D2 parameters, ${ }^{40}$ together with the B97-D3-optimized structures. As seen in Figure 9, the D2 intermolecular dispersive energies correlate very well with the B97-D3 $D_{0}\left(S_{0}\right)$ values for the $1 \mathrm{NpOH} \cdot$ cycloalkane complexes. Since the local environments of all $\mathrm{C}$ and $\mathrm{H}$ atoms in the cycloalkanes are essentially identical, the D3 and D2 energies differ only by a small offset.

Focussing on the near-identical dissociation energies of the cyclopentane and cyclohexane complexes, Figure 10 shows the contribution of each $\mathrm{C}$ and $\mathrm{H}$ atom of the two cycloalkane moieties to the total D2 intermolecular energy. The atoms closer to the naphthol plane contribute much more to the dispersion energy, because of the $1 / R^{6}$ distance dependence, giving larger step increases in Figure 10, compared to the more distant atoms. This shows why $\bar{\alpha}$ is an inadequate predictor of dispersion interaction for molecules consisting of more than a few atoms. It also shows that fine structural details can have disproportionate effects on the interaction energy: In both complexes, the three or four closest $\mathrm{H}$ atoms at $\sim 2.5 \AA$ from the naphthol contribute $\sim 40 \%$ of the total dispersion interaction.

The next series of steps at $3.45-3.65 \AA$ corresponds to the closest $\mathrm{C}$ atoms bound to these $\mathrm{H}$ atoms. The flexible cyclopentane ring approaches the naphthol ring more closely than the rigid cyclohexane ring. In the (most stable) chair conformation of cyclohexane, only three $\mathrm{CH}$ bonds are close to the naphthol ring, while there are four closest $\mathrm{CH}$ bonds in the cyclopentane complex. As 
can be seen in Figure 10, the corresponding cyclopentane atoms make larger contributions to the binding energy, due to the $1 / R^{6}$ dependence of the dispersion interaction, and the cumulative fraction of dispersion energy of the cyclopentane complex lies significantly above that of cyclohexane up to nearly $4 \AA$ from the naphthol plane. The farther methylene groups in cyclohexane contribute only $10 \%$ of the binding energy, similar to the farthest single $\mathrm{CH}_{2}$ group in cyclopentane.

In section III of the Supporting Information, we give the analogous plots of cumulative peratom contributions of the cycloalkanes to the D2 intermolecular dispersion stabilization of the 1-naphthol-cycloalkane face complexes. In all the complexes, the "contact layer" of innermost $\mathrm{CH}_{2}$ units gives rise to about $80 \%$ of the total D2 intermolecular energy. The naphthol $\pi$-face is large enough to accommodate all the cycloalkanes investigated here. For larger solvent molecules full contact of the nearest $\mathrm{CH}_{2}$ layer may not be possible, this is currently being investigated.

The different atoms of the 1-naphthol moiety also contribute differently to the interaction. A graphical per-atom analysis is given in Figures S6, S8 and S10 (SI). The hydroxyl group contributes notably to the interaction. Although the D2 coefficient for oxygen is much lower than that of carbon, the $\mathrm{OH}$ group attracts the cycloalkanes in this direction.

\section{CONCLUSIONS}

Using the using the stimulated-emission pumping resonant two-photon ionization (SEP-R2PI) method, the intermolecular dissociation energies of 1-naphthol-cyclopentane, 1-naphthol-cyclohexane and of two isomers of 1-naphthol-cycloheptane have been accurately bracketed in the $S_{0}$ and $S_{1}$ states to within $<0.1 \mathrm{~kJ} / \mathrm{mol}$, corresponding to a relative uncertainty of $<0.5 \%$. Upon $S_{0} \rightarrow S_{1}$ excitation of the 1-naphthol moiety, the dissociation energies of the 1-naphthol-cycloalkane complexes increase by $0.1 \%$ to $3 \%$.

Three dispersion-corrected density functional methods predict "face"-type structures for all complexes, similar to the recently reported 1-naphthol-cyclopropane face isomer B. ${ }^{28}$ In contrast to the 1-naphthol-cyclopropane "edge" isomer $\mathrm{A},{ }^{28}$ for cyclopentane through cycloheptane the DFT calculations do not predict any structures involving unconventional H-bonds, not even as local minima. Without the D3 dispersion corrections, the calculations predict that none of these complexes are bound. Of the methods tested, the B97 functional with D3 dispersion correction best reproduced the dissociation energies, the differences to experiment being within $\pm 1 \%$ for the cycloalkanes reported here, including the cyclopropane face complex B. ${ }^{28}$ 
The experimental ground-state $D_{0}$ values increase monotonically with increasing size of the cycloalkane moiety, from $17.0 \mathrm{~kJ} / \mathrm{mol}$ for cyclopropane to $22.07 \mathrm{~kJ} / \mathrm{mol}$ for the two cycloheptane complexes. However, the experimental $D_{0}$ values do not correlate linearly with the average molecular polarizabilities $\bar{\alpha}$ of the cycloalkanes. Unexpectedly, we found that the $D_{0}$ of the cyclohexane complex is practically identical to that of 1-naphthol-cyclopentane.

Since the experimental $D_{0}$ values of the cycloalkane face complexes mainly correlate with the dispersive contribution to the binding energy $D_{e}$, as shown in Table III, we analyzed the per-atom contributions to the dispersive interaction, using the atom-atom pairwise D2 dispersion-energy model and parameters of Grimme. ${ }^{40}$ This per-atom analysis reveals the geometric origins of the experimental $D_{0}$ values of these complexes: The methylene groups of the cycloalkane that are closest to the naphthol plane contribute $75-85 \%$ of the dispersive attraction, due to the strong $\left(1 / R^{6}\right)$ distance dependence of the dispersion energy. ${ }^{14}$ Due to the larger conformational flexibility of cyclopentane, its structure adapts to the 1-naphthol partner, whereas the rigid chair-conformer of cyclohexane cannot. As a consequence, four $\mathrm{CH}$ groups of cyclopentane lie closer to the naphthol plane than the three closest $\mathrm{CH}$ groups of cyclohexane; the three remaining methylene groups of cyclohexane are much farther from the naphthol plane, making disproportionately small contributions. The role of the hydroxyl oxygen appears to be largely dispersive, it induces asymmetry in the cycloalkane binding position on the naphthol frame.

This analysis serves to illustrate, in a simplified manner, how structural tuning of dispersion interactions can affect, for example, protein-ligand recognition. These high precision experimental $D_{0}$ values may also serve as useful experimental benchmarks for both correlated ab initio and density functional calculations, and for improving our understanding and modeling of intermolecular interactions.

\section{Supplementary Material}

See supplementary material for additional UV/UV-hole-burning spectra, SEP-R2PI spectra of $1 \mathrm{NpOH} \cdot$ cycloheptane isomer $\mathrm{A}$, tables of Cartesian coordinates of the complexes optimized by the B97-D3 method, and atomic contributions to the D2 intermolecular dispersion energies. 


\section{Acknowledgements}

We thank the Priority Program SPP1807 "Control of London dispersion interactions in molecular chemistry" of the DFG and the Swiss National Science Foundation for support (SNSF grant 200021E-160404).

*leutwyler@dcb.unibe.ch

1 G. C. Maitland, M. Rigby, E. B. Smith, and W. A. Wakeham, Intermolecular Forces: Their Origin and Determination, Clarendon Press, Oxford, 1981.

2 M. Nishio, M. Hirota, and Y. UmeZAwA, The CH/ $\pi$ Interaction: Evidence, Nature, and Consequences, John Wiley \& Sons, 1998.

3 G. R. Desiraju and T. SteIner, The Weak Hydrogen Bond in Structural Chemistry and Biology, Oxford University Press, 2001.

4 T. STEINER, Angew. Chem. Int. Ed. 41, 48 (2002).

5 Y. Umezawa, S. Tsuboyama, K. Honda, J. Uzawa, and M. Nishio, Bull. Chem Soc. Japan. 71, 1207 (1998).

${ }^{6}$ P. E. S. WORMER and A. VAN DER AvoIrd, Chem. Rev. 100, 4109 (2000).

7 M. Mons, I. Dimicoli, and F. Piuzzi, Int. Rev. Phys. Chem. 21, 101 (2002).

8 P. HoвZA, Acc. Chem. Res. 45, 663 (2012).

9 C. D. Sherrill, Acc. Chem. Res. 46, 1020 (2013).

10 J. P. Wagner and P. Schreiner, Angew. Chem. Int. Ed. 54, 12274 (2015).

11 S. Grimme, A. Hansen, J. G. Brandenburg, and C. Bannwarth, Chem. Rev. 116, 5105 (2016).

12 J. A. Frey, C. Holzer, W. Klopper, and S. Leutwyler, Chem. Rev. 116, 5614 (2016).

13 A. Fuji, H. Hayashi, J. W. Park, T. Kazama, N. Mikami, and S. Tsuzuki, Phys. Chem. Chem. Phys. 13, 14131 (2011).

14 R. EISEnsChitz and F. London, Z. Physik 60, 491 (1930).

15 K. E. Riley, M. PitoňÁK, P. JurečKa, and P. HobZa, Chem. Rev. 110, 5023 (2010).

16 H. J. Neusser and H. Krause, Chem. Rev. 94, 1829 (1994).

17 J. E. Braun, T. Mehnert, and H. J. Neusser, Int. J. Mass. Spec. 203, 1 (2000).

18 K. Shibasaki, A. Fujit, N. Mikami, and S. Tsuzuki, J. Phys. Chem. A 110, 4397 (2006). 
K. Shibasaki, A. Fujil, N. Mikami, and S. Tsuzuki, J. Phys. Chem. A 111, 753 (2007).

20 S. Tsuzuki and A. Fujir, Phys. Chem. Chem. Phys. 10, 2584 (2008).

21 S. Tsuzuki, K. Honda, A. Fuji, T. Uchimaru, and M. Mikami, Phys. Chem. Chem. Phys. 10, 2860 (2008).

22 S. Tsuzuki and A. FujiI, Phys. Chem. Chem. Phys. 10, 2584 (2008).

23 T. BÜrgi, T. Droz, and S. LeUtwyler, Chem. Phys. Lett. 225, 351 (1994).

24 T. Droz, T. Bürgi, and S. Leutwyler, J. Chem. Phys. 103, 4035 (1995).

25 T. Bürgi, T. Droz, and S. Leutwyler, Chem. Phys. Lett. 246, 291 (1995).

26 T. BÜrgi, T. Droz, and S. Leutwyler, J. Chem. Phys. 103, 7228 (1995).

27 C. Wickleder, T. Droz, T. Bürgi, and S. Leutwyler, Chem. Phys. Lett. 264, 257 (1997).

28 S. Maity, R. Knochenmuss, C. Holzer, G. Féraud, J. A. Frey, W. Klopper, and S. Leutwyler, J. Chem. Phys. 145, 164304 (2016).

29 Prof. M. Suhm (Göttingen), private communication.

30 H.-L. DAI and R. W. FIELD, Molecular Dynamics and Spectroscopy by Stimulated Emission Pumping, World Scientific, Singapore, 1995.

31 T. Droz, T. Bürgi, and S. Leutwyler, Ber. Bunsenges. Phys. Chem. 99, 429 (1995).

32 C. Wickleder, D. Henseler, and S. Leutwyler, J. Chem. Phys. 116, 1850 (2002).

33 S. Grimme, J. Antony, S. Ehrlich, and H. Krieg, J. Chem. Phys. 132, 154104 (2010).

34 TURBOMOLE V7.0 2016, A Development of University o f Karlsruhe (TH) and Forschungszentrum Karlsruhe GmbH, 1989-2007, TURBOMOLE GmbH, since 2007; available from http: //www.turbomole.com.

35 S. Grimme, J. Comput. Chem. 25, 1463 (2004).

36 J.-D. Chai and M. Head-Gordon, Phys. Chem. Chem. Phys. 10, 6615 (2008).

37 M. J. Frisch, G. W. Trucks, H. B. Schlegel, G. E. Scuseria, M. A. Robb, J. R. Cheeseman, G. Scalmani, V. Barone, B. Mennucci, G. A. Petersson, and et Al, Gaussian 09 Revision A.02, 2009, Gaussian, Inc., Wallingford CT, 2009.

38 F. A. Balmer, P. Ottiger, C. Pfaffen, and S. Leutwyler, J. Phys. Chem. A 117, 10702 (2013).

39 F. A. Balmer, P. Ottiger, and S. Leutwyler, J. Phys. Chem. A 119, 10462 (2015).

40 S. Grimme, J. Comput. Chem. 27, 1787 (2006).

41 P. Kowalewski, H.-M. Frey, D. Infanger, and S. Leutwyler, J. Phys. Chem. A 119, 11215 (2015). 
42 C. P. A. Anconi, C. S. Nascimento, H. F. Dos Santos, and W. B. De Almeida, Chem. Phys. Lett. 418, 459 (2006).

43 M. Zierhut, W. Roth, S. Dümmler, and I. Fischer, Chem. Phys. 305, 123 (2004).

44 U. Even, A. Amirav, S. Leutwyler, M. J. Ondrechen, Z. Berkovitch-Yellin, and J. JortNER, Faraday Discuss. Chem. Soc. 73, 153 (1982).

45 S. Leutwyler and J. Jortner, J. Phys. Chem. 91, 5558 (1987).

46 J. Bösiger and S. Leutwyler, Chem. Rev. 90, 489 (1990).

47 D. R. Lide and H. Frederikse, Handbook of Chemistry and Physics 78th Ed., 1997.

48 http://www.chemspider.com/Chemical-Structure.8908.html.

49 A. D. Crowell and R. B. Steele, J. Chem. Phys. 34, 1347 (1961).

50 M. J. Ondrechen, Z. Berkovitch-Yellin, and J. Jortner, J. Am. Chem. Soc. 103, 6586 (1981). 
TABLE I. Dissociation energies $D_{0}\left(S_{0}\right)$ and $D_{0}\left(S_{1}\right)$ and spectral shifts $\delta \tilde{\nu}$ of the 1-naphthol-cycloalkane complexes.

\begin{tabular}{lcccccr}
\hline \hline \multirow{2}{*}{ Complex/isomer } & \multicolumn{2}{c}{$D_{0}\left(S_{0}\right)$} & & \multicolumn{2}{c}{$D_{0}\left(S_{1}\right)$} & $\delta$ \\
\cline { 2 - 3 } & $\mathrm{cm}^{-1}$ & $\mathrm{~kJ} / \mathrm{mol}$ & & $\mathrm{cm}^{-1}$ & $\mathrm{~kJ} / \mathrm{mol}$ & $\mathrm{cm}^{-1}$ \\
\hline Cyclopropane/edge & $1283 \pm 3$ & $15.34 \pm 0.03$ & & $1354 \pm 3$ & $16.20 \pm 0.04$ & -71.5 \\
Cyclopropane/face & $1417 \pm 10$ & $17.0 \pm 0.1$ & & $1416 \pm 10$ & $16.9 \pm 0.1$ & 1.9 \\
Cyclopentane & $1691 \pm 6$ & $20.23 \pm 0.07$ & & $1742 \pm 7$ & $20.84 \pm 0.08$ & -51.3 \\
Cyclohexane & $1700 \pm 3$ & $20.34 \pm 0.04$ & & $1702 \pm 3$ & $20.36 \pm 0.04$ & -1.7 \\
Cycloheptane/isomer A & $1845 \pm 8$ & $22.07 \pm 0.10$ & & $1884 \pm 9$ & $22.53 \pm 0.10$ & -38.5 \\
Cycloheptane/isomer B & $1845 \pm 8$ & $22.07 \pm 0.10$ & & $1878 \pm 9$ & $22.47 \pm 0.10$ & -32.9 \\
\hline \hline
\end{tabular}


TABLE II. Experimental and calculated dissociation energies $D_{0}\left(S_{0}\right)$ (in $\mathrm{kJ} / \mathrm{mol}$ ) of the 1-naphthol face complexes with cyclopropane, cyclopentane, cyclohexane and cycloheptane, using the dispersion-corrected DFT methods B97-D3, B3LYP-D3 and $\omega$ B97X-D methods. The B97-D3 change in zero-point vibrational energy $\triangle \mathrm{ZPVE}$ is also given.

\begin{tabular}{|c|c|c|c|c|c|}
\hline \multirow[t]{2}{*}{ Complex } & Experimental & B97-D3 & B97-D3 & B3LYP-D3 & $\omega \mathrm{B} 97 \mathrm{X}-\mathrm{D}$ \\
\hline & \multicolumn{5}{|c|}{$\triangle \mathrm{ZPVE}$} \\
\hline Cyclopropane edge & $15.35 \pm 0.03$ & 15.75 & 3.65 & 15.52 & 14.85 \\
\hline Cyclopropane face & $17.00 \pm 0.10$ & 16.67 & 3.41 & 17.07 & 19.23 \\
\hline Cyclopentane & $20.23 \pm 0.07$ & 20.17 & 3.89 & 21.67 & 24.11 \\
\hline Cyclohexane & $20.34 \pm 0.04$ & 20.51 & 3.20 & 22.11 & 24.49 \\
\hline Cycloheptane isomer A & $22.07 \pm 0.10$ & 22.38 & 3.10 & 24.09 & 26.11 \\
\hline Cycloheptane isomer B & $22.07 \pm 0.10$ & 22.27 & 3.20 & 24.03 & 26.65 \\
\hline Cycloheptane isomer C & - & 22.08 & 2.99 & 23.72 & 26.13 \\
\hline Cycloheptane isomer D & - & 21.95 & 3.02 & 23.60 & 26.0 \\
\hline
\end{tabular}


TABLE III. B97-D3/def2-TZVPP calculated binding energies $D_{e}\left(S_{0}\right)$ of the 1-naphthol--cycloalkane complexes (in $\mathrm{kJ} / \mathrm{mol}$ ) with and without the $\mathrm{D} 3$ correction. The fourth column gives the $D_{e}$ without the dispersion correction (the - sign means that the complex is unbound).

\begin{tabular}{lcccc}
\hline \hline Complex & $\begin{array}{c}D_{e}\left(S_{0}\right) \text { with D3 D3 Energy } \\
\text { with D3 }\end{array}$ & $\begin{array}{c}D_{e}\left(S_{0}\right) \\
\text { without D3 }\end{array}$ & $\begin{array}{c}\text { Average cycloalkane } \\
\text { polazability } \bar{\alpha}\left(\AA^{3}\right)\end{array}$ \\
\hline Cyclopropane edge & 19.41 & 17.35 & 2.06 & 5.66 \\
Cyclopropane face & 20.09 & 34.76 & -14.67 & 5.66 \\
Cyclopentane & 24.06 & 43.88 & -19.82 & 9.15 \\
Cyclohexane & 23.71 & 42.85 & -19.14 & 10.87 \\
Cycloheptane isomer A & 25.46 & 45.84 & -20.38 & 12.8 \\
Cycloheptane isomer B & 25.47 & 46.59 & -21.12 & 12.8 \\
Cycloheptane isomer C & 25.06 & 45.14 & -20.08 & \\
Cycloheptane isomer D & 24.97 & 45.36 & -20.39 & \\
\hline \hline
\end{tabular}




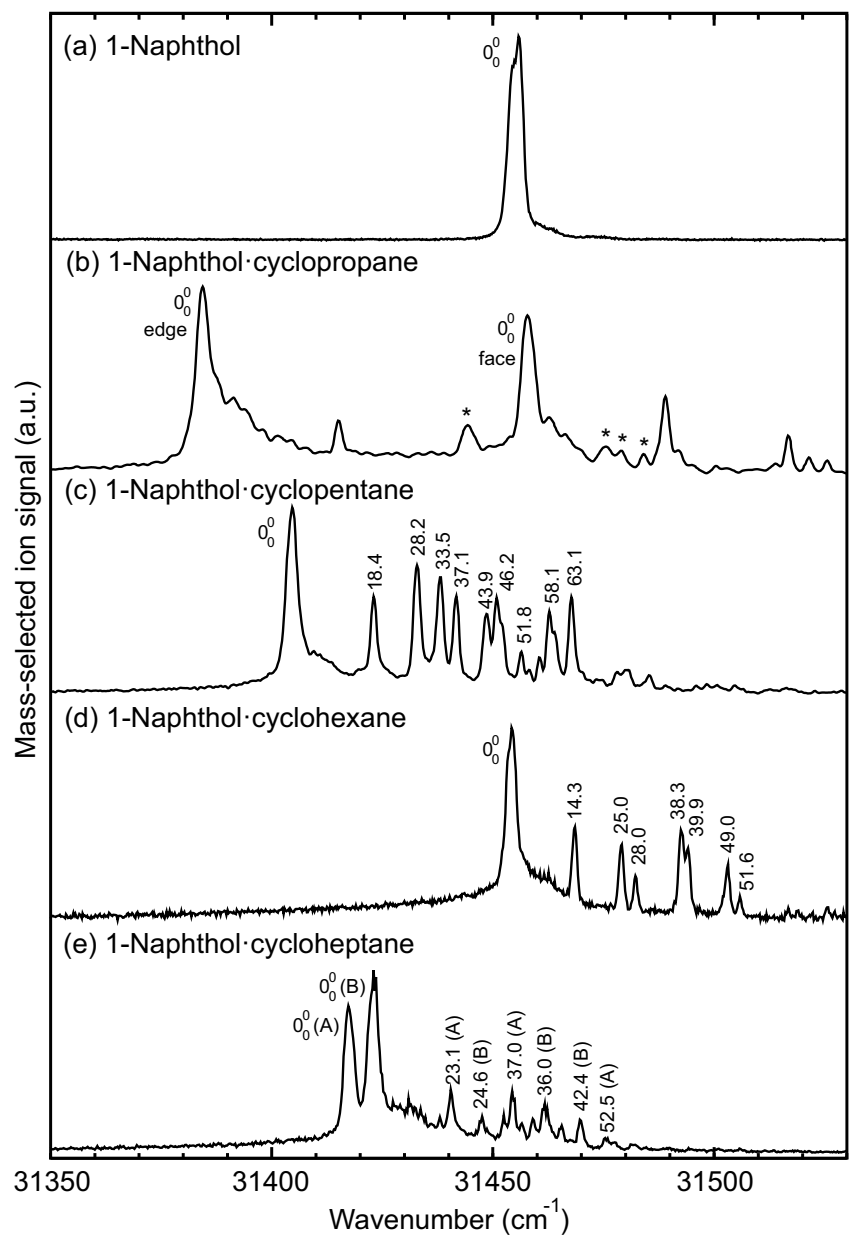

FIG. 1. One-color resonant-two-photon ionization spectra of (a) 1-naphthol, (b) 1-naphthol-cyclopropane, (c) 1-naphthol-cyclopentane, (d) 1-naphthol-cyclohexane and (e) 1-naphthol-cycloheptane. Intermolecular vibrations in the $S_{1}$ state are labeled with their energies above the origins. 


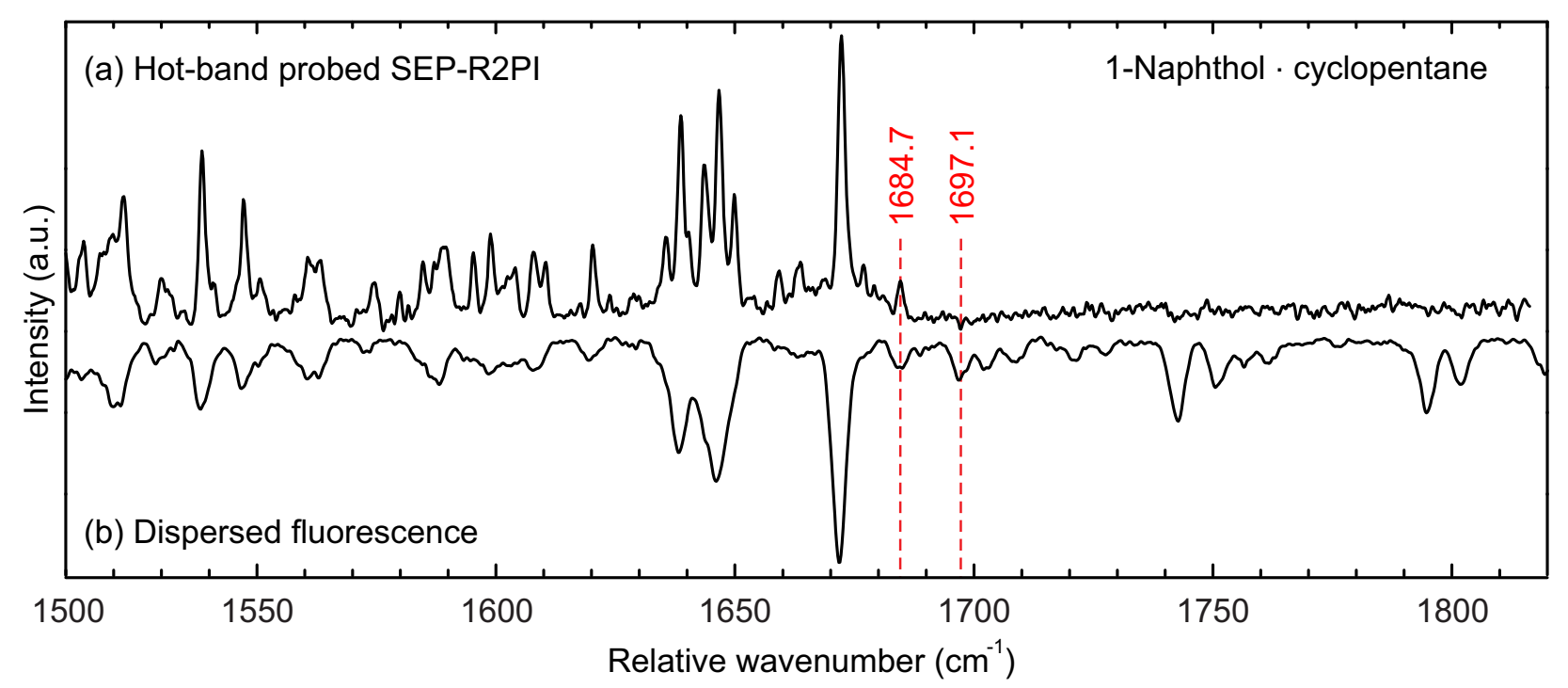

FIG. 2. (a) Hot-band probed SEP-R2PI spectrum and (b) dispersed fluorescence spectrum (inverted) of 1-naphthol-cyclopentane. The $D_{0}\left(S_{0}\right)$ is bracketed by the dashed lines at 1684.7 and $1697.1 \mathrm{~cm}^{-1}$. The horizontal axis is the difference between the pump $\left(0_{0}^{0}\right.$ band, $\left.31404.6 \mathrm{~cm}^{-1}\right)$ and dump laser frequencies. 


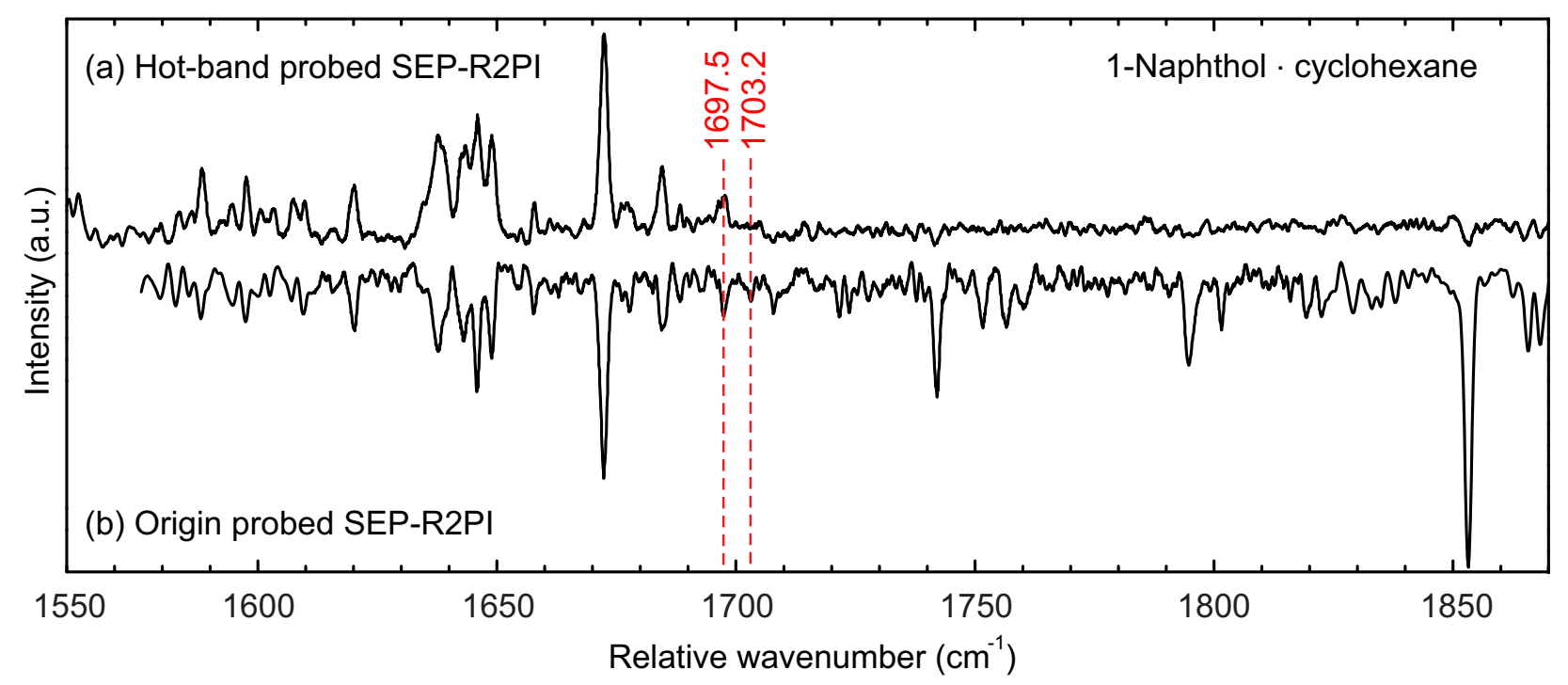

FIG. 3. (a) Hot-band probed SEP-R2PI spectrum and (b) origin-probed SEP-R2PI spectrum of 1naphthol-cyclohexane. The $D_{0}\left(S_{0}\right)$ is bracketed by the bands at 1697.5 and $1703.2 \mathrm{~cm}^{-1}$ (red dashed lines). The horizontal axis is the difference between the pump ( $0_{0}^{0}$ band, $\left.31454.5 \mathrm{~cm}^{-1}\right)$ and dump laser frequencies. 


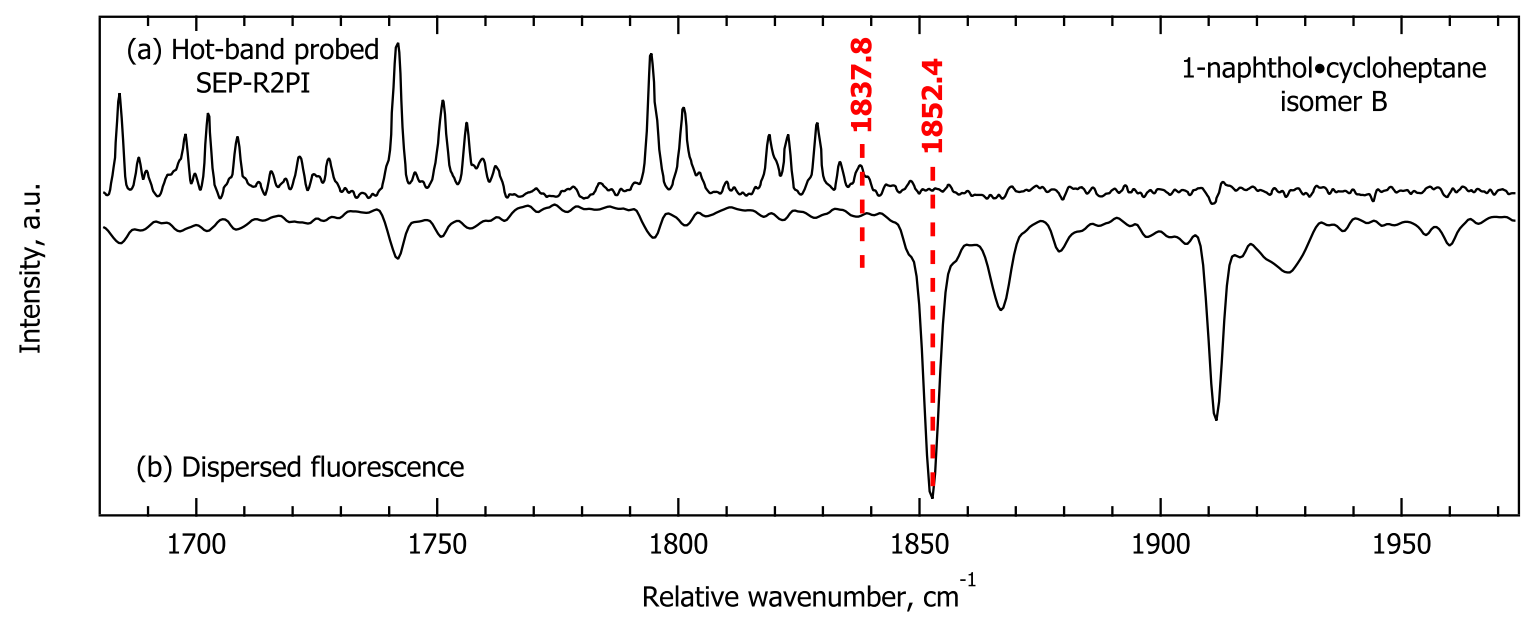

FIG. 4. (a) Hot-band probed SEP-R2PI spectrum and (b) fluorescence spectrum (inverted) of the 1naphthol-cycloheptane isomer B complex. The $D_{0}\left(S_{0}\right)$ is bracketed by the dashed lines at 1837.8 and $1852.4 \mathrm{~cm}^{-1}$. The horizontal axis is the difference between the pump $\left(0_{0}^{0}\right.$ band at $\left.31423.0 \mathrm{~cm}^{-1}\right)$ and dump laser frequencies. 
(a) 1-Naphthol•cyclopropane, face isomer
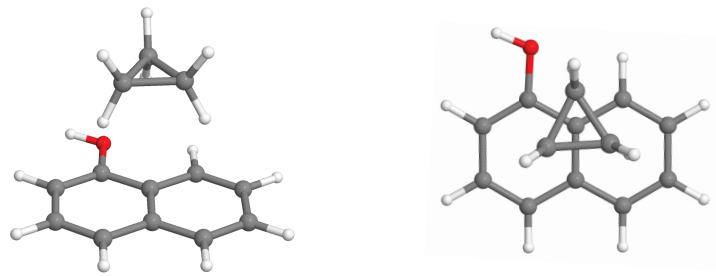

(b) 1-Naphthol•cyclopropane, edge isomer
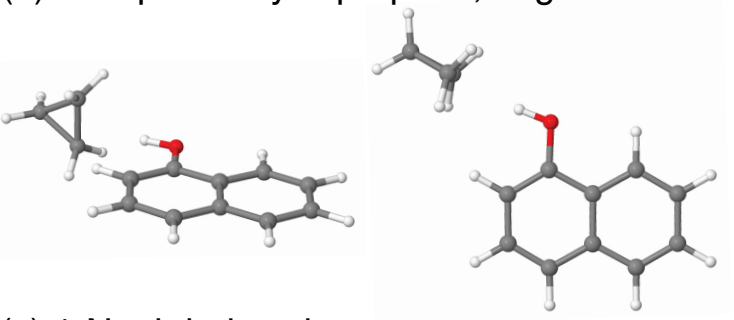

(c) 1-Naphthol•cyclopentane
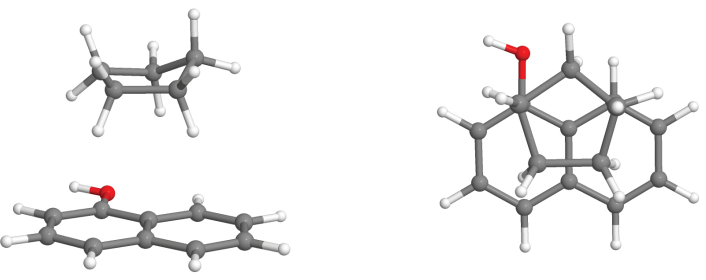

(d) 1-Naphthol•cyclohexane
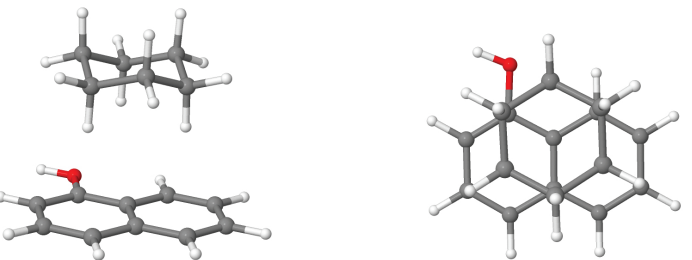

FIG. 5. The B97-D3/def2-TZVPP optimized structures of the complexes of 1-naphthol with cyclopropane (a and b), cyclopentane (c) and cyclohexane (d). 
(a) 1-Naphthol•cycloheptane, isomer A
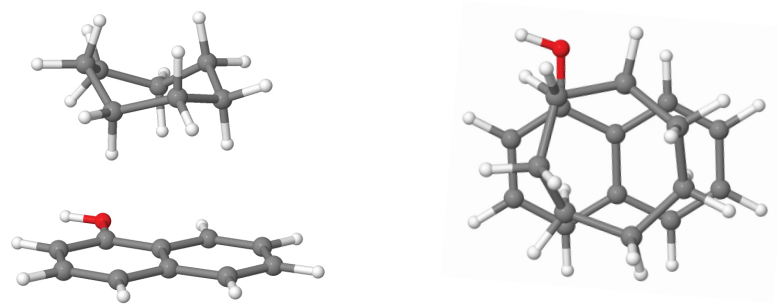

(b) 1-Naphthol•cycloheptane, isomer B
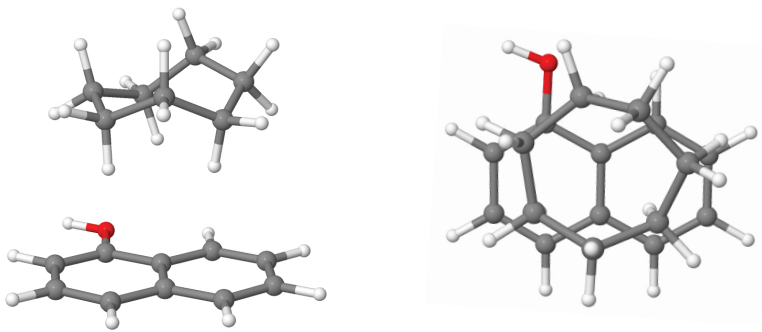

(c) 1-Naphthol•cycloheptane, isomer C
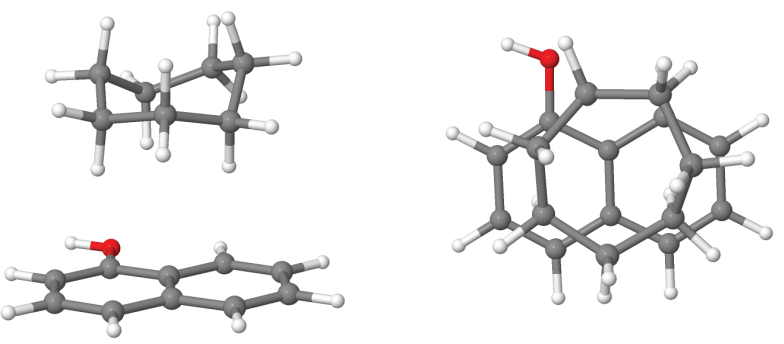

(d) 1-Naphthol•cycloheptane, isomer D
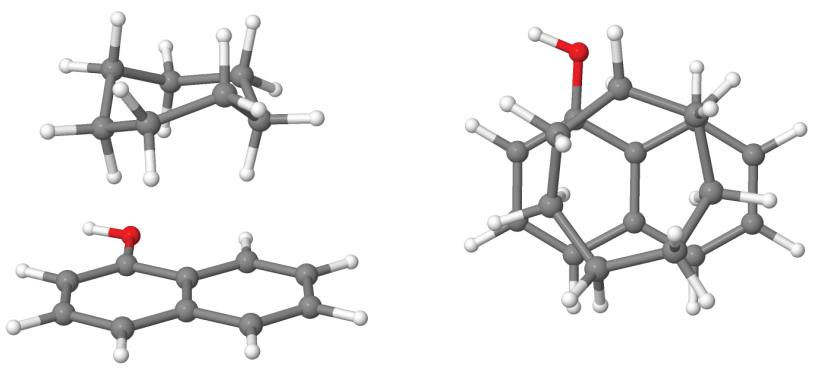

FIG. 6. The B97-D3/def2-TZVPP optimized structures of the four lowest-energy isomers of the 1naphthol·cycloheptane complex. 


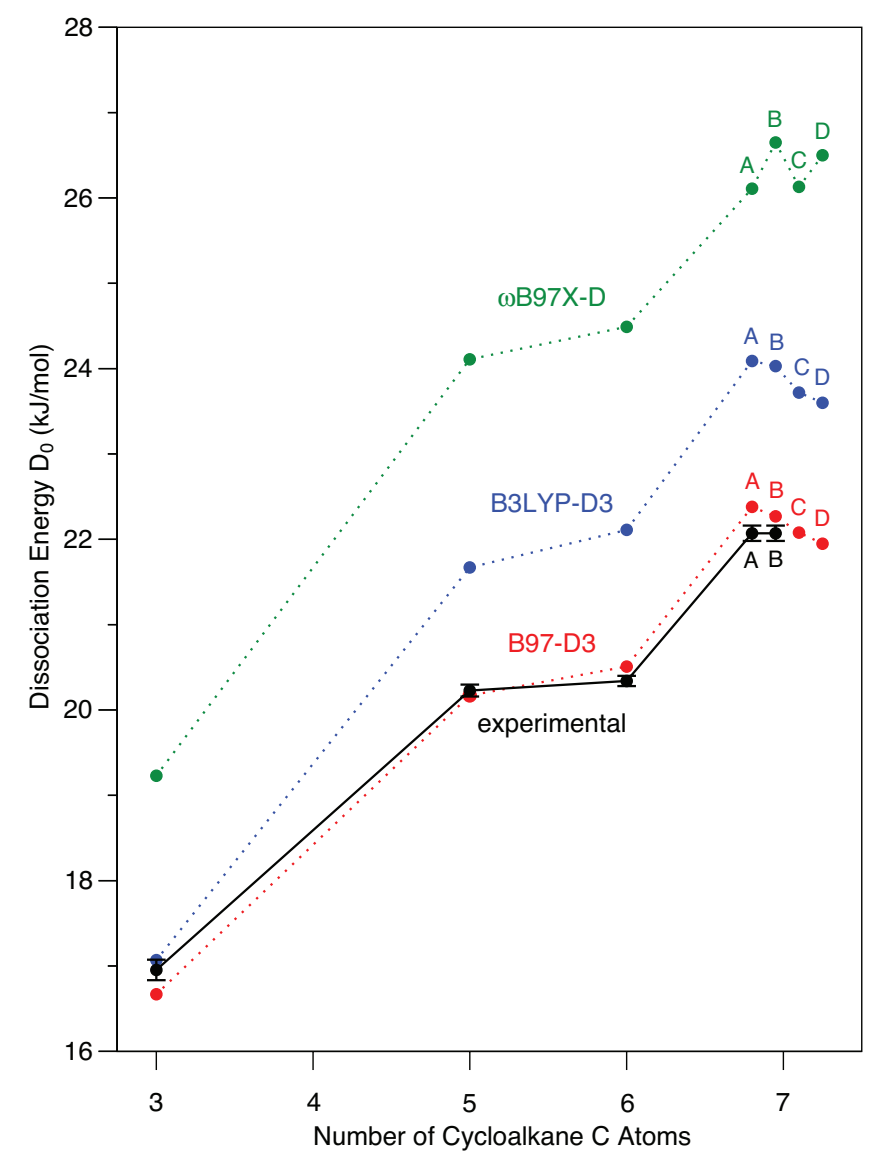

FIG. 7. Comparison of experimental (black) and calculated (color) $D_{0}\left(S_{0}\right)$ dissociation energies of the 1-naphthol·cycloalkane face isomers from cyclopropane to cycloheptane. 


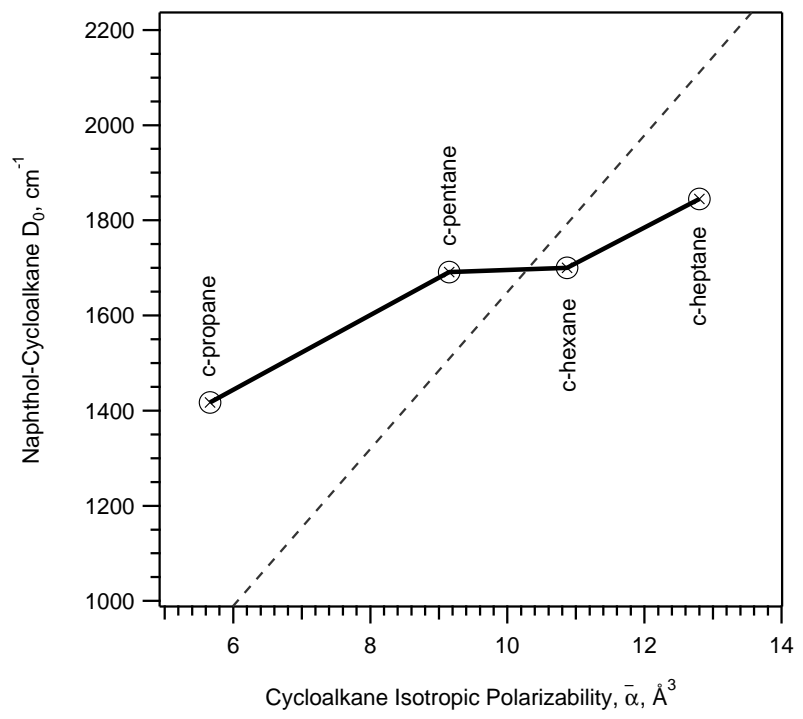

FIG. 8. Dissociation energies of the 1-naphthol-cycloalkane complexes vs. the average polarizability $\bar{\alpha}$ of the cycloalkane. The dashed line is a linear fit with zero intercept, as is expected from London theory. 


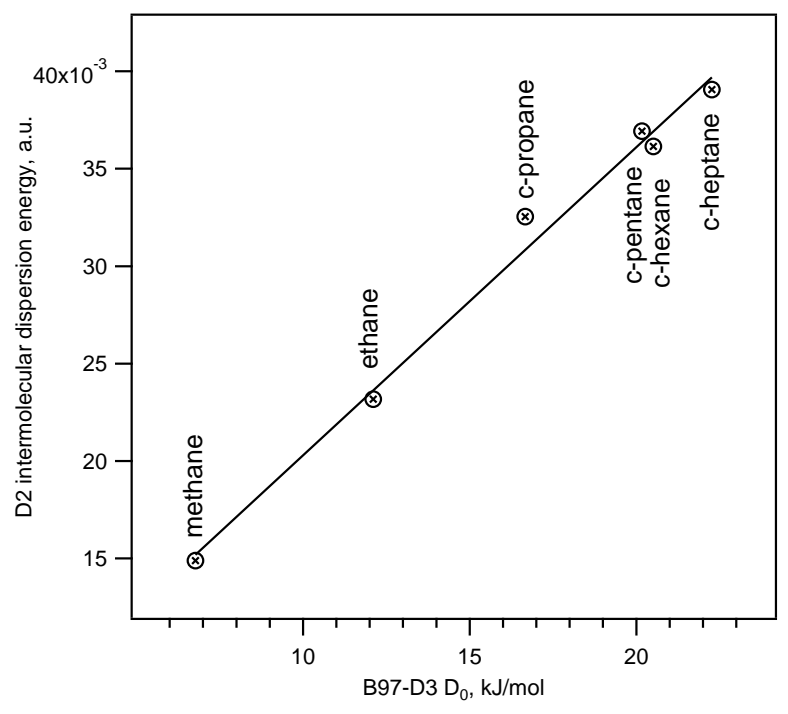

FIG. 9. Correlation of D2 dispersion energy with B97-D3 $D_{0}$ values for the 1-naphthol.S complexes with $\mathrm{S}=$ methane, ethane, cyclopropane, cyclopentane, cyclohexane and cycloheptane. The line is a linear fit to the data. 


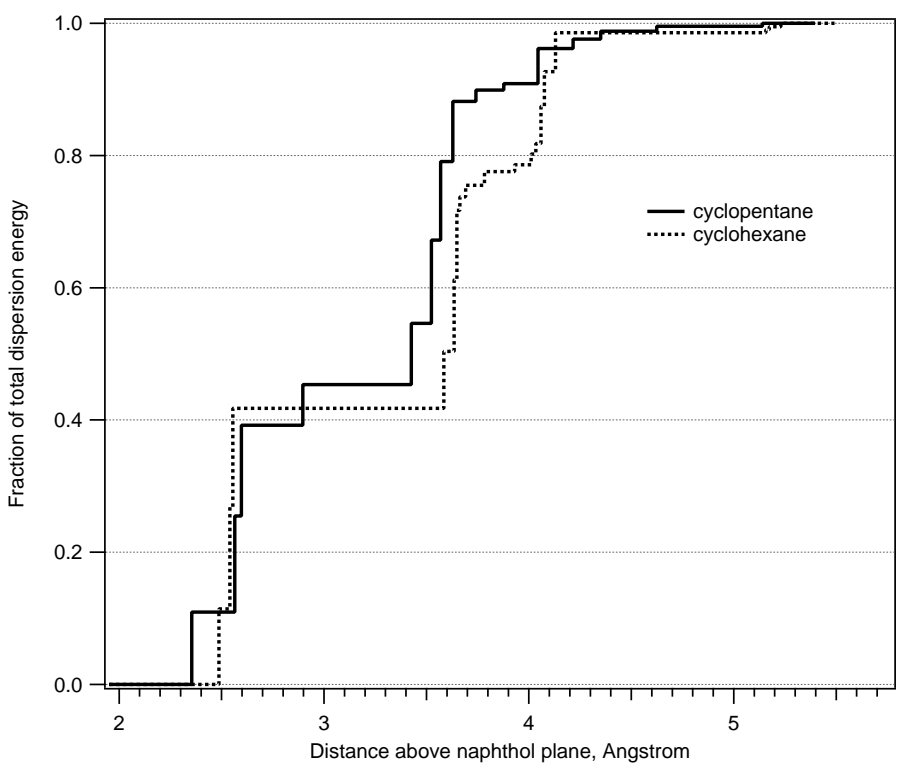

FIG. 10. Cumulative fractional $\mathrm{D} 2$ dispersion energy vs. $\mathrm{C}$ and $\mathrm{H}$ atom distances from the $1 \mathrm{NpOH}$ plane, for $1 \mathrm{NpOH} \cdot$ cyclopentane and $1 \mathrm{NpOH} \cdot$ cyclohexane, using the B97-D3 optimized geometries. 